\title{
GESTÃO AMBIENTAL E DESAGREGAÇÃO DAS RELAÇÕES INTERGOVERNAMENTAIS NO BRASIL: DOS DESENCONTROS NORMATIVOS À NECESSÁRIA PACTUAÇÃO FEDERATIVA
}

\author{
Anderson Henrique Araújo \\ anderson.hsa@gmail.com \\ Renato Luis Pinto Miranda \\ renatoluispm@gmail.com
}

\begin{abstract}
Resumo - O presente estudo busca estudar a relação entre o perfil institucional do atual arranjo federativo brasileiro e a gestão fiscal ambiental dos municípios da região Nordeste. Percorre-se, dessa forma, a discussão sobre as concepções de centralização e descentralização na teoria federativa, investigando-se como e como isso impacta na gestão fiscal ambiental dos entes municipais. A pesquisa traz uma análise descritiva de dados secundários sobre as transferências voluntárias de natureza ambiental entre os entes federativos. As análises demonstram um baixo índice de integração entre os diferentes níveis de governo, sendo a autonomia institucional concentrada nos níveis estadual e federal, enquanto a incumbência da gestão ambiental vai sendo dissolvida no âmbito da frágeis administrações municipais.
\end{abstract}

Palavras-chave: Federalismo; Gestão Ambiental; Transferências Fiscais.

\section{ENVIRONMENTAL MANAGEMENT AND DISAGREGATION OF INTERGOVERNMENTAL RELATIONS IN BRAZIL: FROM REGULATORY DISENGUES TO THE NECESSARY FEDERATIVE PACTUATION}

\begin{abstract}
This study aims to study the relationship between the institutional profile of the current Brazilian federative arrangement and environmental fiscal management of the municipalities in the Northeast. Runs through it, therefore, the discussion on the concepts of centralization and decentralization in federal theory, is investigating how and how this impacts on environmental fiscal management of municipal entities. The survey provides a descriptive analysis of secondary data on voluntary transfers of environmental among federal entities. The analysis shows a low rate of integration between the different levels of government, and institutional autonomy concentrated at the state and federal levels, while the task of environmental management will be dissolved within the fragile municipal administrations.
\end{abstract}

Keywords: Federalism; Environmental management; Fiscal transfers.

\section{INTRODUÇÃO}

A promulgação da Constituição Federal de 1988 trouxe uma série de implicações ao perfil institucional do federalismo brasileiro, redefinindo competências e redesenhando as relações intergovernamentais sob diversos aspectos. No âmbito da gestão ambiental, foram atribuídas responsabilidades aos municípios, comoa proteção e o controledo meio ambiente; o combate à poluição;ações de educação ambiental; e a preservação das florestas, fauna e flora. Apesar de tal descentralização de atribuições, após promulgada a Carta Constitucional, o país vem atravessando um processo de recentralização das receitas tributárias nas mãos do governo federal, de modo que, embora tenham sido atribuídas aos municípios as competências da gestão ambiental, estes acabam por se tornar meros executores nessa dimensão, uma vez que, tanto as receitas tributárias para 
financiamento das políticas ambientais, como a elaboração legislativa originária de normas ambientais- sobre defesa, controle e fiscalização - concentram-se no plano do governo federal.

Nesse contexto, a presente investigação busca compreender como a conformação das relações intergovenamentais no Brasil impactam na gestão fiscal ambiental dos municípios nordestinos. Objetiva, desta forma, abordar a interdependência entre a gestão das políticas ambientais e a arquitetura institucional do arranjo federativo brasileiro, tomando como escopo de análise os municípios da região Nordeste. Tal intento subdivide-se no estudo teórico da gestão ambiental, sob o ponto de vista das relações federativas; na investigação dos determinantes institucionais das transferências intergovernamentais destinadas à gestão fiscal ambiental; e na análise do possível impacto dessas transferências sobre as políticas ambientais dos municípios nordestinos. Enquanto método de investigação, após a discussão teórica, foi realizada uma análise descritiva de dados secundários - extraídos da base do Tesouro Nacional(FINBRA) e portais de transparência pública - acerca das transferências voluntárias de natureza ambiental aos municípios estudados.

\section{OS DETERMINANTES CONJUNTURAIS DA RECENTRALIZAÇÃO FEDERATIVA.}

As teorias que discutem o perfil e a composição do arranjo federativo vêm ganhando proeminência conforme os desdobramentos histórico-conjunturais do seu surgimento, de modo que as noções de centralização e descentralização federativa e fiscal oscilam conforme as necessidades e a correlação de forças de cada contexto.

A partir da crise do WelfareState nos países centrais, em meados da década de 1970, a PublicChoiceTheory assume proeminência, enquanto corrente teórica de abordagem da dinâmica federativa, no sentido de refrear a ampliação e a, alegada, ineficiência do poder central, preconizando a competição entre as distintas esferas governamentais, como forma de assegurar a otimização operativa das políticas públicas (OLIVEIRA, 2007). Essa perspectiva acredita que o federalismo descentralizado e competitivo viria a beneficiar os cidadãos que, podendo circular entre os distintos territórios, poderiam exigir uma ação estatal mais eficiente na composição das políticas públicas (LYNCH, 2004). Dessa forma, a abordagem neoliberal da dinâmica federativa prescreve o enfraquecimento do poder do governo central ${ }^{1}$, aliado à inibição de possíveis tentativas de intervenção por parte das províncias, constituindo-se, assim,

\footnotetext{
${ }^{1}$ Buchanan (1995) compartilha o seu posicionamento, nesse âmbito, com os precursores do neoliberalismo, Milton Friedman e Friedrich Hayek. Consideram os governos como agentes monopolistas, os quais devem ter o seu poder de intervenção limitado pela disciplina do mercado, no qual os governos subnacionais competem pela mobilidade dos cidadãos e dos empresários num contexto liberal (HARMES, 2007).
} 
uma espécie de descentralização/centralização específica, para promover o livre mercado. (DYE, 1990; HARMES, 2007).

A fragilidade institucional a que foram submetidos os Estados, no decorrer das décadas de 1980 e 1990 - consideradas as suas especificidades históricas e os respectivos graus de desenvolvimento -, fez com que eles se tornassem incapazes de proporcionar um nível mínimo de estabilidade e de segurança, necessário ao desenvolvimento dos mercados, ensejando, a partir de então, uma reconsideração interna do próprio mainstream, no sentido de sanar tais debilidades. Conforme se pode depreender das recomendações constantes nos relatórios do Banco Mundial, os pressupostos da PublicChoiceTheory foram, de algum modo, flexibilizados, pois, em se considerando a existência de mercados imperfeitos e da informação imperfeita, naturalmente, não se poderia deixar de levar em conta o fato de a ação de um dado agente individual causar externalidades sobre a ação dos demais (WORLD BANK, 2000). A competição entre os entes subnacionais, em regime de mercado, deveria, então, ser atenuada, considerando-se, também, outras dimensões, além de, unicamente, a maximização de "lucros" pelos agentes.

A New InstitutionalEconomics, embora mantenha consigo a noção de que a competição interjurisdicional traz ganhos de eficiência para o setor público, adverte estarem tais benefícios condicionados à constituição de um arranjo institucional apropriado, capaz de manter a "concorrência", entre os governos subnacionais, dentro dos parâmetros de uma "competição saudável", coibindo, para tanto, o surgimento de práticas e de instrumentos possivelmente nocivos ao entorno sistêmico das relações intergovernamentais. Assim, em contrariedade à analogia estabelecida entre a concorrência intergovernamental e à lógica dos mercados competitivos, desenvolvida por atores privados, a New InstitutionalEconomics reage, criticamente, à "canonização" da competição federativa, enquanto postulado, invariavelmente, promotor da eficiência no setor público (AFFONSO, 2003). Instaura-se, nesse contexto, um processo de redefinição das relações intergovernamentais a partir do qual o governo central figura como articulador, regulador e avalista dos arranjos institucionais - dentre os quais, o federativo -, delineados de forma "adequada" a garantir o bom funcionamento da dinâmica concorrencial. Num cenário marcado pela necessidade de fortalecimento das instituições, os esforços deixam de centrar-se na preponderância das "falhas de mercado" ou das "falhas de Estado", edificando-se o que se pode chamar de "federalismo institucional", caracterizado enquanto um arranjo capaz de assegurar o cumprimento dos, então proeminentes, compromissos de ajuste macroeconômico (OLIVEIRA, 2007).

Nesses termos, a complexidade da questão federativa no Brasil reside, justamente, na conexão entre as suas múltiplas faces, as quais vão desde a sustentação das metas fiscais até a constituição de um arranjo federativo voltado para o esvaziamento do poder dos estados- 
membros, em prol de uma maior "eficiência" na execução das ações em seu território pelo governo central (REZENDE et al., 2007). Assim, a recentralização federativa, proeminente a partir dos anos 2000, segue seu curso no âmago das diversas legislações que compõem seus arranjos institucionais, seja no que diz respeito à gestão ambiental, fiscal ou em outras esferas de articulação da ação pública intergovernamental.

\section{O MUNICIPALISMO AMBIENTAL BRASILEIRO EM ASPECTOS TEÓRICOS E JURÍDICOS.}

O processo decentralizador/recentralizador atravessado pelo Brasil a partir do século XX, interfere diretamente na execução financeira dos entes federados, e, portanto, dos Municípios. Sob o prisma jurídico, o caráter partilhado da Constituição Federal de 1988 tornou-se, em ordem hierárquica, a maior referência sobre as competências municipais para com a gestão ambiental, minuciada por diplomas infra-constitucionaiscomoa Política Nacional do Meio ambiente (Lei 6938/1981), e a Lei Complementar 140/2011.

Segundo o artigo 225, da Magna Carta,

Todos têm direito ao meio ambiente ecologicamente equilibrado, bem de uso comum do povo e essencial à sadia qualidade de vida, impondo-se ao Poder Público e à coletividade o dever de defendê-lo e preservá-lo para as presentes e futuras gerações. (BRASIL, 1988)

Dentro dessa perspectiva, é também responsabilidade dos Munícipios prover mecanismos para alcançar o ambiente equilibrado, como ressalta.

Embora se destaque o caráter decentralizador da carta, o ambiente propicio para a descentralização não ocorreu instantaneamente.

[...] esperava-se que, com a descentralização das políticas públicas, os estados e municípios assumissem as atribuições de gestão das políticas públicas. Isto, entretanto, não ocorreu porque os estados e municípios, apesar de terem recebido uma parcela maior de recursos, não dispunham de meios para exercer tal papel e, mesmo que tivessem, não tinham interesse em assumir algumas atribuições que, apesar de constarem na constituição e em algumas leis que foram recepcionadas por esta, não o fizeram, pois, a União ainda atuava. (SCARDUA,2003, p.82)

Tal efeito foi fortemente sentido nas políticas públicas ambientais, que apesar de um caráter decentralizador anterior a carta magna, ainda tinha a União como grande executor ${ }^{2}$. Entretanto, a própria Lei 6938/81 buscou decentralizar a gestão pública ambiental através do Sistema Nacional de Meio ambiente (SISNAMA), composto por um conjunto articulado de órgãos e entes federados com o objetivo de melhorar a qualidade ambiental.

2 Carlo (2006) ressalta que a carta constitucional concedeu amplo poder de atuação municipal no que se refere a políticas ambientais. Todavia, tal autonomia ficava concentrada nos interesses locais, sendo os poderes regionais e nacionais, responsabilidades de estados e União, respectivamente. 
Anterior a constituição de 1988, o SISNAMA foi um passo inicial na busca da corresponsabilidade da matéria ambiental. Institucionalmente, criou importantes instrumentos norteadores da gestão ambiental no Brasil ${ }^{3}$. Não obstante, considera-se como instrumentos de fiscalização e controle na referida Lei:

\footnotetext{
“Art $9^{\circ}$-São instrumentos da Política Nacional do Meio Ambiente:

I o estabelecimento de padrões de qualidade ambiental;

II o zoneamento ambiental;

III a avaliação de impactos ambientais;

IV o licenciamento e a revisão de atividades efetiva ou potencialmente poluidoras;

$\mathrm{V}$ os incentivos à produção e instalação de equipamentos e a criação ou absorção de tecnologia, voltados para a melhoria da qualidade ambiental;

VI a criação de espaços territoriais especialmente protegidos pelo Poder Público federal, estadual e municipal, tais como áreas de proteção ambiental, de relevante interesse ecológico e reservas extrativistas;

VII o sistema nacional de informações sobre o meio ambiente;

VIII o Cadastro Técnico Federal de Atividades e Instrumentos de Defesa Ambiental;

IX as penalidades disciplinares ou compensatórias ao não cumprimento das medidas necessárias à preservação ou correção da degradação ambiental.

X a instituição do Relatório de Qualidade do Meio Ambiente, a ser divulgado anualmente pelo Instituto Brasileiro do Meio Ambiente e Recursos Naturais Renováveis IBAMA;

XI a garantia da prestação de informações relativas ao Meio Ambiente, obrigando-se o Poder Público a produzi-las, quando inexistentes;

XII o Cadastro Técnico Federal de atividades potencialmente poluidoras e/ou utilizadoras dos recursos ambientais.

XIII instrumentos econômicos, como concessão florestal, servidão ambiental, seguro ambiental e outros". (BRASIL, 1981, p.3)
}

Embora destacado a importância e o caráter decentralizador da Lei 6.938/81, a mesma apresenta algumas limitações em seus ordenamentos jurídicos. Os órgãos que compõe o Sisnama carecem de recursos estruturais, orçamentários e capital humano para o seu correto funcionamento. A situação é mais caótica nos Municípios, quando analisamos as limitações orçamentárias e deinfraestrutura.

Enfatizado por autores que desenvolveram estudos sobre a gestão ambiental no início do século XXI, tais como Scurda(2003), Carlo (2006) e Leme (2010), o projeto de Lei que regulamenta o artigo 23 da constituição de 1988 e altera a Lei 6938/81 é apresentada em 2011, já num contexto histórico-institucional marcado pelos imperativos de recentralização.A lei complementar 140/2011, indica as formas de cooperação entre as esferas governamentais para o exercício do mandato ambiental, no tocante a proteção das paisagens naturais notáveis, à proteção do meio ambiente, ao combate à poluição em qualquer de suas formas e, à preservação das florestas, da fauna e da flora, responsabilidade de União, Estados e Municípios. Não obstante, considera o artigo $3^{\circ}$ :

"I proteger,defender e conservar o meio ambiente ecologicamente equilibrado, promovendo gestãodescentralizada, democrática e eficiente;

3 Além do já ressaltado SISNAMA, criou-se o Conselho Nacional do Meio ambiente(CONAMA), compendio de setores governamentais, empresariais e da sociedade civil com foco na fiscalização e controle ambiental. 
II garantiro equilíbrio do desenvolvimento socioeconômico com a proteção do meio ambiente,observando a dignidade da pessoa humana, a erradicação da pobreza e a redução das desigualdades sociais eregionais;

III harmonizaras políticas e ações administrativas para evitar a sobreposição de atuação entre os entesfederativos, de forma a evitar conflitos de atribuições e garantir uma atuação administrativa eficiente;

IV garantira uniformidade da política ambiental para todo o País, respeitadas as peculiaridades regionaise locais". (BRASIL; 2011.p.1)

É ressalvável a importância da descentralização na Lei complementar, conforme o artigo $4^{\circ}$, que sublinha a importância de convênios, acordos de cooperação técnica e outros instrumentos complementares entre os poderes públicos. Entretanto, o referido artigo ressalta a delegação de atribuições e execução de ações intra órgãos federados, o que, na prática, configura-se um conflito de forças, onde a grande maioria dos Municípios brasileiros, dado as próprias especificidades, sai em desvantagem.

No quesito atribuições, a Lei complementar estabelece para a União o caráter controlador, na condição de fiscalizador de toda a gestão ambiental, inclusive cobrando e controlando os demais entes federados. Aos Municípios, cabe cumprir as políticas nacionais e estaduais em seus respetivos territórios, dentre outras atribuições dispostas no artigo $9^{\circ}$ :

"I executar e fazer cumprir, em âmbito municipal, as Políticas Nacional e Estadual de Meio Ambiente e demais políticas nacionais e estaduais relacionadas à proteção do meio ambiente;

II exercer a gestão dos recursos ambientais no âmbito de suas atribuições; III formular, executar e fazer cumprir a Política Municipal de Meio Ambiente;

IV promover, no Município, a integração de programas e ações de órgãos e entidades da administração pública federal, estadual e municipal, relacionados à proteção e à gestão ambiental;

$\mathrm{V}$ articular a cooperação técnica, científica e financeira, em apoio às Políticas Nacional, Estadual e Municipal de Meio Ambiente;

VI promover o desenvolvimento de estudos e pesquisas direcionados à proteção e à gestão ambiental, divulgando os resultados obtidos;

VII organizar e manter o Sistema Municipal de Informações sobre Meio Ambiente;

VIII prestar informações aos Estados e à União para a formação e atualização dos Sistemas Estadual e Nacional de Informações sobre Meio Ambiente"

IX elaborar o Plano Diretor, observando os zoneamentos ambientais;

$\mathrm{X}$ definir espaços territoriais e seus componentes a serem especialmente protegidos;

XI promover e orientar a educação ambiental em todos os níveis de ensino e a conscientização pública para a proteção do meio ambiente;

XII controlar a produção, a comercialização e o emprego de técnicas, métodos e substâncias que comportem risco para a vida, a qualidade de vida e o meio ambiente, na forma da lei;

XIII exercer o controle e fiscalizar as atividades e empreendimentos cuja atribuição para licenciar ou autorizar, ambientalmente, for cometida ao Município;

XIV observadasas atribuições dos demais entes federativos previstas nesta Lei Complementar,promover o licenciamento ambiental das atividades ou empreendimento. (BRASIL; 2011.P.5/6)

Aliado as limitações impostas pelo perfil do atual arranjo federativo brasileiro, outro desafio dos municípios é fazer valer a função ambiental, seguindo os requisitos da legislação.Os dispositivos jurídicos indicam a ressaltam a importância da descentralização, porém no âmbito das finanças públicas, as combalidas contas das prefeituras demonstram a incapacidade de executar as 
políticas ambientais. O contexto é ainda mais agravante nas cidades de menor população, geralmente com baixa dinâmica econômica e quase total dependência dos recursos federais ${ }^{4}$.

A solução buscada pelas prefeituras é a parceira com órgãos federais e/ou consórcios com Organizações da Sociedade Civil de Interesse Público (OSCIPS), titulação fornecida pelo Ministério da Justiça, onde empresas que estabeleçam parceiras possam receber isenções tributárias.

Diante da indisponibilidade quadro técnico qualificado, muitas vezes as parceiras não são consolidadas. Não obstante, obrigações de natureza fiscal, como aquelas estabelecidas na Lei Complementar 101/2000(Lei de Responsabilidade Fiscal), dificultam as ações ambientais dos municípios. Mais próximas das demandas locais, cabe as prefeituras prover mecanismos para assegurar a população a qualidade ambiental no território de suas cidades, quer seja com recursos próprios, ou através de parceiras entre União e /ou Estados. Todavia, o mecanismo é apenas formal:

\begin{abstract}
Até os dias atuais, o federalismo ambiental trino brasileiro persiste restrito apenas a seu enunciado formal. A estreiteza das regras adotadas para estruturar as relações federativas no campo ambiental debilita o pleno exercício do mandato municipal e alimenta permanente tensão entre a dimensão do poder-dever das atribuições ambientais dos municípios e o abandono a que estão relegados para exercê-las. As atividades que exigem cooperação intergovernamental têm sido desenhadas casuisticamente, programa a programa. A corresponsabilidade em matéria ambiental traz consigo necessidade de regras e mecanismos efetivos para o exercício da cooperação. Inexistindo condições operacionais para o exercício da competência comum, os Municípios brasileiros se encontram estão no desamparo para cumprir com seu mandato ambiental - se não dispõem dos recursos e capacidades requeridos por seus próprios meios, a tendência é a inércia e a abdicação do exercício de seu mandato ambiental. (NEVES, 2014, P.33/34)
\end{abstract}

Apesar da dificuldade na aplicação e de uma agenda local ambiental, é fundamental o apoio dos municípios na implantação da agenda ambiental e da política de meio ambiente. Leme (2016) destaca que a superação das dificuldades está centrada na resolução de alguns gargalos:

[...]atuação coordenada do governo federal no sentido de dar sinergias às políticas estaduais e municipais de meio ambiente;

- incentivo à criação ou à continuidade de programas federal e estaduais de fortalecimento da gestão ambiental local, envolvendo-se capacitação, assistência técnica, apoio para a estruturação física e suporte financeiro para os municípios que estruturarem a gestão ambiental local;

- capacitação dos técnicos das prefeituras, dos agentes políticos e da sociedade civil, levando-se em conta as atribuições que os municípios devem exercer e as realidades e os desafios locais;

- fortalecimento das instâncias de articulação política entre entes federados, como as comissões técnicas tripartites;

- criação de fóruns de articulação e intercâmbio de ordem técnica entre as prefeituras e os demais órgãos públicos de meio ambiente;

- incentivo aos consórcios públicos como estratégia para os pequenos municípios e para lidar com questões regionais; e

- fortalecimento das capacidades de gestão dos fundos públicos de meio ambiente, inclusive criando-se mecanismos de financiamento das políticas públicas de forma conjunta entre fundos nacionais, estaduais e municipais. (2016, p.171)

4 Com destaque para o Fundo de Participação dos Municípios (FPM) e transferências do Fundo de Manutenção e Desenvolvimento da Educação Básica e de Valorização dos Profissionais da Educação (FUNDEB). 
Afim de verificar a execução ambiental nas cidades, o próximo item analisará a execução financeira dos municípios e pesquisa de informações municipais (MUNICI), dados que comparados e descritos, demonstram a situação das cidades nordestinas.

\section{FINANÇAS MUNICIPAIS E GESTÃO AMBIENTAL: UMA ANÁLISE PARA A REGIÃO NORDESTE}

Para a compreensão da gestão municipal ambiental, foi selecionado a região nordeste. A mesma concentra a maior região litorânea e o maior semiárido do Brasil, tornando a questão ambiental relevante. Não obstante, é a região que concentra o maior número de Municípios brasileiros, totalizando 1794 cidades, 32,21\% do total. A mesma está dividida em 9 Estados, conforme descrição no quadro 1 .

Quadro 1 - Municípios Nordestinos e população censitária

\begin{tabular}{|c|c|c|} 
Número de municípios selecionados & \multicolumn{2}{c|}{ População Total } \\
\hline & Estado & 3.120 .922 \\
\hline $\mathbf{1 0 2}$ & Alagoas & 14.021 .432 \\
\hline $\mathbf{4 1 7}$ & Bahia & 8.448 .055 \\
\hline $\mathbf{1 8 4}$ & Ceará & 6.569 .683 \\
\hline $\mathbf{2 1 3}$ & Maranhão & 3.766 .834 \\
\hline $\mathbf{1 8 5}$ & Paraíba & 8.796 .032 \\
\hline $\mathbf{2 2 4}$ & Pernambuco & 3.119 .015 \\
\hline $\mathbf{1 6 7}$ & Piauí & 3.168 .133 \\
\hline $\mathbf{7 5}$ & Rio Grande do Norte & 2.068 .031 \\
\hline
\end{tabular}

Fonte: Censo 2010.Elaboração própria

Os dados utilizados serão divididos em duas fontes. A primeira, é a pesquisa de informações municipais, divulgada pelo instituto brasileiro de Geografia e Estatística (IBGE), desde o ano 2005. A série inalgural, que utiliza como fonte os dados de 2002, dedicou uma publicação suplementar para análise do meio ambiente brasileiro. Nas edições seguintes, o tópico ambiental foi restrito a uma seção na publicação consolidada, alternado a quantidade de informações sobre a gestão ambiental.

A segunda fonte, são os dados financeiros das cidades, são disponibilizados pela Secretaria do Tesouro Nacional (STN), base Finanças do Brasil (FINBRA)5. Ressalta-se que a função "gestão ambiental", com dotações orçamentárias para investimentos na área ambiental foi disponibilizada na base FINBRA a partir de 2002. Em 2005, os dados foram ampliados, sendo possível identificar os montantes oriundos de convênios entre as cidades e demais entes da federação, e as subfunções da gestão ambiental: preservação ambiental, controle ambiental, recuperação de áreas degradadas, recursos hídricos, meteorologia e outras despesas ambientais.

\footnotetext{
${ }^{5}$ A base FINBRA disponibiliza dados sobre as finanças públicas municipais, iniciando a série em 1994. Disponível em: http://www.tesouro.fazenda.gov.br/pt_PT/contas-anuais.
} 
Elegendo os municípios que contemplavam informações completas e sólidas para toda a série, serão utilizados indicadores, que denominaremos de índices de gestão pública ambiental, tornando possível comparar o esforço e desempenho do ente público, no que se refere a gestão ambiental. A partir desses indicadores, será realizada uma análise estatística descritiva, afim de verificar o gasto financeiro dos pequenos municípios nordestinos com gestão ambiental, e o nível de parceiras entre os entes federados (estados e municípios). Embora inexistam estudos que avaliem a capacidade de os indicadores demonstrarem o desenvolvimento ambiental, considera-se um mecanismo de bastante relevância para análises financeiras.

Índice

Quadro 2 - Índices de avaliação orçamentária ambiental

Índice de Gestão Pública ambiental

Razão entre Gestão ambiental e PIB

Índice de gestão ambiental por área $\left(\mathrm{Km}^{2}\right)$

Índice de Gestão

Ambiental per capita

Índice de transferências Estaduais

Índice de transferências Federais
Fórmula

$$
\frac{\text { Gestão Ambiental }}{\text { Despesas Correntes }}
$$

$\frac{\text { Gestão Ambiental }}{\text { Despesas Correntes }}$

$$
\begin{gathered}
\frac{\text { Gestão Ambiental }}{\text { Área Total }} \\
\frac{\text { Gestão Ambiental }}{\text { População Censitária }}
\end{gathered}
$$

Tranferências Estaduais

Despesas Correntes

$$
\frac{\text { Tranferências Federais }}{\text { Despesas Correntes }}
$$

Objetivo

Analisar o comprometimento dos das despesas com gestão ambiental em relação a despesa total.

Avaliar a participação da despesa ambiental e o Produto Interno Bruto municipal.

Avaliar os gastos ambientais e área territorial dos municípios (em R\$).

Indicar os gastos ambientais, em relação ao quantitativo de habitantes de cada município (em R\$).

Verificar a participação dos convênios ambientais entre estados e munícipios na composição da receita total. Verificar a participação dos convênios ambientais entre União e munícipios na composição da receita total.

Fonte: Adaptação de Almeida (2010). Elaboração própria

A partir dos dados da pesquisa MUNIC 2002, 2013 e 2015, selecionou-se as variáveis que expressassem o impacto da gestão ambiental nas cidades, e os impasses federativos. Primeiramente, o pessoal ocupado em 2013 expressa um número considerável de pessoas sem vínculo (ou vinculo estável) para todos os estados da região em destaque. Isso indica que a pauta ambiental nas cidades está mais venerável de cortes orçamentários ou crises financeiras. Todavia, o número ocupado de pessoal vem aumentando para todas as regiões, como demonstra Leme (2010), cuja análise comparativa entre os anos de 2002/08, indicou 5866 e 7851 servidores, respectivamente. 
Quadro 3. Pessoal ocupado na área de meio ambiente, por vínculo empregatício (2013)

\begin{tabular}{|c|c|c|c|c|c|c|}
\hline \multicolumn{7}{|l|}{ Grandes Regiões } \\
\hline $\begin{array}{c}\text { e } \\
\text { Unidades da } \\
\text { Federação }\end{array}$ & $\begin{array}{l}\text { Total } \\
(1)\end{array}$ & Estatutários & CLT & $\begin{array}{c}\text { Somente } \\
\text { comissionados }\end{array}$ & Estagiários & $\begin{array}{l}\text { Sem vínculo } \\
\text { permanente }\end{array}$ \\
\hline Brasil & 61295 & 27902 & 4912 & 12957 & 2618 & 12878 \\
\hline Nordeste & 13042 & 4870 & 371 & 4207 & 237 & 3354 \\
\hline Maranhão & 1400 & 379 & 22 & 462 & 12 & 522 \\
\hline Piauí & 616 & 58 & 100 & 323 & 4 & 131 \\
\hline Ceará & 2909 & 1110 & 31 & 692 & 14 & 1062 \\
\hline Rio Grande do Norte & 1213 & 578 & 3 & 465 & 82 & 85 \\
\hline Paraíba & 1075 & 530 & 1 & 312 & 28 & 204 \\
\hline Pernambuco & 1263 & 475 & 2 & 507 & 39 & 240 \\
\hline Alagoas & 1121 & 424 & 120 & 234 & 24 & 319 \\
\hline Sergipe & 490 & 277 & 6 & 185 & 2 & 20 \\
\hline Bahia & 2955 & 1039 & 86 & 1027 & 32 & 771 \\
\hline
\end{tabular}

Fonte: IBGE. Pesquisa de informações municipais 2013

No tocante a capacidade de financiamento ambiental, é considerável o aumento de municípios com fundo municipal de meio ambiente. O crescimento especifico levanta dúvidas sobre a confiabilidade, como expressa Leme (2010). Todavia, a autora esclarece um forte esforço do Ministério do Meio Ambiente (MMA) para criação dos fundos específicos.

Quadro 4. Número de municípios com fundo municipal de meio ambiente

\begin{tabular}{|c|c|c|c|}
\hline $\begin{array}{c}\text { Grandes Regiões } \\
\mathbf{e} \\
\text { Unidades da Federação }\end{array}$ & $\mathbf{2 0 0 2}$ & $\mathbf{2 0 1 3}$ & $\begin{array}{c}\text { Crescimento } \\
\text { em \% }\end{array}$ \\
\hline Brasil & $\mathbf{2 0 0}$ & $\mathbf{2 3 8 6}$ & $\mathbf{1 1 9 3}$ \\
\hline Nordeste & $\mathbf{6}$ & $\mathbf{4 5 2}$ & $\mathbf{7 5 3 3}$ \\
\hline Maranhão & - & 48 & - \\
\hline Piaú́ & - & 19 & - \\
\hline Ceará & 1 & 68 & 6800 \\
\hline Rio Grande do Norte & - & 28 & - \\
\hline Paraíba & - & 10 & - \\
\hline Pernambuco & - & 34 & - \\
\hline Alagoas & 1 & 14 & 1400 \\
\hline Sergipe & - & 14 & - \\
\hline Bahia & 4 & 217 & 5425 \\
\hline
\end{tabular}

Fonte: IBGE. Pesquisa de informações municipais 2002 e 2013

Acerca da legislação ambiental nos municípios, o quadro 5 demonstra que o número de cidades com algum dispositivo legal na região nordeste ainda está aquém do necessário. Dados 
as próprias características dos municípios situados na região, é indispensável algum dispositivo jurídico, até mesmo no plano diretor para a temática ambiental.

Quadro 5. Municípios com Legislação especifica ambiental em 2013

\begin{tabular}{|c|c|c|c|c|c|c|c|}
\hline \multirow{3}{*}{$\begin{array}{c}\text { Grandes Regiões } \\
\text { e } \\
\text { Unidades da } \\
\text { Federação }\end{array}$} & \multicolumn{7}{|c|}{ Municípios } \\
\hline & & \multicolumn{6}{|c|}{ Com legislação específica para tratar da questão ambiental } \\
\hline & Total & Total & $\begin{array}{l}\text { Capítulo } \\
\text { ou } \\
\text { artigo na } \\
\text { Lei } \\
\text { Orgânica }\end{array}$ & $\begin{array}{l}\text { Código } \\
\text { ambiental }\end{array}$ & $\begin{array}{c}\text { Lei de } \\
\text { criação } \\
\text { de Unidades } \\
\text { de } \\
\text { Conservação }\end{array}$ & $\begin{array}{c}\text { Capítulo } \\
\text { ou } \\
\text { artigo } \\
\text { no } \\
\text { Plano } \\
\text { Diretor }\end{array}$ & $\begin{array}{c}\text { Diversas } \\
\text { leis }\end{array}$ \\
\hline Brasil & 5570 & 3649 & 1112 & 749 & 85 & 379 & 1322 \\
\hline Nordeste & 1794 & 871 & 385 & 241 & 19 & 91 & 134 \\
\hline Rio Grande do Norte & 167 & 55 & 28 & 11 & 2 & 7 & 7 \\
\hline Paraíba & 223 & 72 & 47 & 10 & 1 & 5 & 9 \\
\hline Pernambuco & 185 & 83 & 39 & 8 & 1 & 18 & 17 \\
\hline Alagoas & 102 & 41 & 13 & 15 & 2 & 4 & 7 \\
\hline Sergipe & 75 & 29 & 9 & 11 & - & 4 & 5 \\
\hline Bahia & 417 & 286 & 79 & 145 & 5 & 15 & 41 \\
\hline
\end{tabular}

Fonte: IBGE. Pesquisa de informações municipais 2013.

Os convênios entre órgão federativos é uma realidade consolidada na gestão pública ambiental brasileira. Em relação a essa matéria, a MUNIC 2013 considera 6 programas federais de inserção nos municípios:

1. Coletivo Educadores: No âmbito da educação ambiental, esse programa tem por objetivo articular uma rede de colaboradores da região onde é inserido, visando diagnosticar e contribuir para o desenvolvimento socioambiental.

2. Sala Verde: Também relacionado a educação ambiental, busca democratizar o acesso a toda informação socioambiental, utilizando os paços públicos ou privados. Seu objetivo é a criar um espaço de busca de informação e desenvolvimento de pensamento crítico acerca das demais locais e regionais.

3. Circuito Tela Verde: Mostra nacional de produção audiovisual, com conteúdo socioambiental.

4. Conferência Nacional Infanto-juvenil pelo Meio Ambiente - CNIJMA: Encontros e diálogos entre estudantes, professores, juventude e comunidade com foco na sustentabilidade. Está diretamente ligado a política Nacional de Educação ambiental, sendo, portanto de responsabilidade compartilhada com o Ministério da Educação(MEC). 
5. Educação Ambiental no plano de recursos sólidos: Busca inserir os princípios da educação ambiental no plano nacional de recursos sólidos municipais, disposto na Lei $\mathrm{n}^{\circ}$ $12.305 / 2010$

\section{Sustentabilidade ambiental das instituições públicas, como a Agenda Ambiental na}

Adminis-tração-A3P: Programa de gestão socioambiental na administração pública. Busca, dentre outros itens, um Uso racional dos recursos naturais e bens públicos, gestão adequada dos resíduos gerados, Qualidade de vida no ambiente de Trabalho, sensibilização e capacitação do servidor, licitações sustentáveis e compras sustentáveis.

A análise dos programas descritos nos Municípios fica abaixo do considerado relevante, mas segue uma tendência nacional, dado que a média brasileira também é baixa. Seguindo uma tendência fora da media, o estado do Ceará se desponta, com o maior quantitativo de cidades contempladas, proporcionalmente, possivelmente fruto do esforço político local.

Quadro 6. Municípios, total e com programas implantados em parceria com o Governo Federal (2013)

\begin{tabular}{|c|c|c|c|c|c|c|c|c|}
\hline \multirow[b]{3}{*}{$\begin{array}{c}\text { Grandes Regiões } \\
\text { e } \\
\text { Unidades da } \\
\text { Federação }\end{array}$} & \multicolumn{8}{|c|}{$\begin{array}{l}\text { Municípios } \\
\end{array}$} \\
\hline & \multirow[b]{2}{*}{ Total } & \multirow[b]{2}{*}{ Total } & \multicolumn{6}{|c|}{ Programa implantado } \\
\hline & & & $\begin{array}{l}\text { Coletivo } \\
\text { Educador }\end{array}$ & $\begin{array}{l}\text { Sala } \\
\text { Verde }\end{array}$ & $\begin{array}{c}\text { Circuito } \\
\text { Tela } \\
\text { Verde }\end{array}$ & $\begin{array}{l}\text { Conferência } \\
\text { Infanto- } \\
\text { juvenil } \\
\text { pelo Meio } \\
\text { Ambiente }\end{array}$ & $\begin{array}{c}\text { Educação } \\
\text { Ambiental } \\
\text { no Plano } \\
\text { de } \\
\text { Gestão de } \\
\text { Resíduos } \\
\text { Sólidos }\end{array}$ & $\begin{array}{l}\text { Sustentabilidade } \\
\text { ambiental das } \\
\text { instituições } \\
\text { públicas, como a } \\
\text { Agenda } \\
\text { Ambiental } \\
\text { na Adminis- } \\
\text { tração-A3P }\end{array}$ \\
\hline Brasil & 5570 & 1902 & 244 & 362 & 95 & 504 & 1419 & 292 \\
\hline Nordeste & 1794 & 562 & 62 & 84 & 33 & 225 & 393 & 95 \\
\hline Maranhão & 217 & 63 & 8 & 2 & 2 & 24 & 48 & 4 \\
\hline Piauí & 224 & 42 & 4 & 7 & 3 & 16 & 29 & 3 \\
\hline Ceará & 184 & 108 & 13 & 21 & 11 & 65 & 70 & 37 \\
\hline Rio Grande do Norte & 167 & 34 & 4 & 3 & 2 & 11 & 22 & 7 \\
\hline Paraíba & 223 & 46 & 2 & 5 & 2 & 13 & 33 & 5 \\
\hline Pernambuco & 185 & 70 & 11 & 9 & 2 & 26 & 51 & 11 \\
\hline Alagoas & 102 & 37 & 5 & 5 & 2 & 18 & 26 & 3 \\
\hline Sergipe & 75 & 37 & 4 & 4 & 2 & 6 & 34 & 5 \\
\hline Bahia & 417 & 125 & 11 & 28 & 7 & 46 & 80 & 20 \\
\hline
\end{tabular}

Fonte: IBGE. Pesquisa de informações municipais 2013.

A agenda 21 é uma inciativa desenvolvida na conferência Rio-92, no âmbito do desenvolvimento sustentável. Seu objeto é dadoas características socioeconômicas da nação, construir um plano estratégico com objetivo de desenvolver a localidade com participação de vários atores.

"Os benefícios gerados pelos processos de Agenda 21 vêm de mudanças resultantes de reflexões, discussões, resolução de conflitos, integração entre atores envolvidos e sinergismo da proposta de desenvolvimento sustentável como um todo" (MALHEIROS et.al.; 2008,P. 18) 
Quanto a agenda 21 no Nordeste, os dados informam que após a euforia da efetivação do plano no Brasil, vem diminuindo a adesão e continuidade do projeto nos Munícipios do Nordeste brasileiro. Embora os estudos recentes busquem analisar a efetividade e qualidade dos propostos nas agendas, o grande problema reside na adesão e continuidade do projeto nas cidades.

Quadro 7. Número de Municípios que elaboraram a agenda 21.

\begin{tabular}{|c|c|c|c|c|c|c|c|}
\hline \multirow{2}{*}{$\begin{array}{c}\text { Grandes } \\
\text { Regiões } \\
\text { e } \\
\text { Unidades } \\
\text { da } \\
\text { Federação }\end{array}$} & \multicolumn{4}{|c|}{2002} & \multicolumn{3}{|c|}{2015} \\
\hline & Total & Iniciada & Não iniciou & Desconhece & Iniciada & Não iniciou & Desconhece \\
\hline Brasil & 5570 & 1652 & 3329 & 576 & 1225 & 3908 & 436 \\
\hline Nordeste & 1794 & 1144 & 590 & 56 & 509 & 1171 & 114 \\
\hline Maranhão & 217 & 136 & 75 & 6 & 41 & 164 & 12 \\
\hline Piauí & 224 & 118 & 93 & 11 & 42 & 165 & 17 \\
\hline Ceará & 184 & 108 & 65 & 10 & 86 & 86 & 12 \\
\hline $\begin{array}{l}\text { Rio Grande } \\
\text { do Norte }\end{array}$ & 167 & 115 & 45 & 6 & 41 & 113 & 13 \\
\hline Paraíba & 223 & 174 & 47 & 2 & 53 & 150 & 20 \\
\hline Pernambuco & 185 & 123 & 61 & 1 & 58 & 117 & 10 \\
\hline Alagoas & 102 & 68 & 31 & 3 & 26 & 72 & 4 \\
\hline Sergipe & 75 & 46 & 24 & 5 & 26 & 45 & 4 \\
\hline Bahia & 417 & 256 & 149 & 12 & 136 & 259 & 22 \\
\hline
\end{tabular}

Fonte: IBGE. Pesquisa de informações municipais 2002 e 2015

Analisando os dados faz finanças públicas das cidades, a informação municipal ambiental engloba dados de receitas e despesas. No tocante a receita, é possível identificar o montante oriundo de transferências entre os entes federados (União e Estados), direcionados a cada município. Em relação a despesa é possível identificar o volume executado da função "gestão ambiental" e suas respectivas subfunções: preservação e conservação ambiental; controle ambiental; recuperação de áreas degradadas; recursos hídricos; meteorologia e demais subfunções de gestão ambiental.

O indicador de gestão pública ambiental (quadro 8) para o período de 2002/14 não apresentou resultados médios positivos para nenhum estado nordestino.

Quadro 8. Índice de Gestão Pública ambiental para os pequenos municípios (em \%)

\begin{tabular}{|c|c|c|c|c|c|c|c|c|c|c|c|c|c|}
\hline Estado & $\mathbf{2 0 0 2}$ & $\mathbf{2 0 0 3}$ & $\mathbf{2 0 0 4}$ & $\mathbf{2 0 0 5}$ & $\mathbf{2 0 0 6}$ & $\mathbf{2 0 0 7}$ & $\mathbf{2 0 0 8}$ & $\mathbf{2 0 0 9}$ & $\mathbf{2 0 1 0}$ & $\mathbf{2 0 1 1}$ & $\mathbf{2 0 1 2}$ & $\mathbf{2 0 1 3}$ & $\mathbf{2 0 1 4}$ \\
\hline ALAGOAS & 0,00 & 0,00 & 0,00 & 0,00 & 0,00 & 0,00 & 0,00 & 0,00 & 0,00 & 0,00 & 0,00 & 0,00 & 0,00 \\
\hline BAHIA & 0,00 & 0,00 & 0,00 & 0,00 & 0,00 & 0,00 & 0,00 & 0,00 & 0,00 & 0,00 & 0,00 & 0,00 & 0,00 \\
\hline CEARÁ & 0,00 & 0,00 & 0,00 & 0,00 & 0,00 & 0,00 & 0,00 & 0,00 & 0,00 & 0,00 & 0,00 & 0,00 & 0,00 \\
\hline MARANHÃO & 0,00 & 0,00 & 0,00 & 0,00 & 0,00 & 0,00 & 0,00 & 0,00 & 0,00 & 0,00 & 0,00 & 0,00 & 0,00 \\
\hline PARAIIBA & 0,00 & 0,00 & 0,00 & 0,00 & 0,00 & 0,00 & 0,00 & 0,00 & 0,00 & 0,00 & 0,00 & 0,00 & 0,00 \\
\hline PERNAMBUCO & 0,00 & 0,00 & 0,00 & 0,00 & 0,00 & 0,00 & 0,00 & 0,00 & 0,00 & 0,00 & 0,00 & 0,00 & 0,00 \\
\hline PIAUÍ́ & 0,00 & 0,00 & 0,00 & 0,00 & 0,00 & 0,00 & 0,00 & 0,00 & 0,00 & 0,00 & 0,00 & 0,00 & 0,00 \\
\hline $\begin{array}{c}\text { RIO GRANDE } \\
\text { DO NORTE }\end{array}$ & 0,00 & 0,00 & 0,00 & 0,00 & 0,00 & 0,00 & 0,00 & 0,00 & 0,00 & 0,00 & 0,00 & 0,00 & 0,00 \\
\hline SERGIPE & 0,00 & 0,00 & 0,00 & 0,00 & 0,00 & 0,00 & 0,00 & 0,00 & 0,00 & 0,00 & 0,00 & 0,00 & 0,00 \\
\hline
\end{tabular}

Fonte: FINBRA. Elaboração do Autor 
Já os resultados máximos (quadro 9) para os índices de gestão ambiental indica diferentes realidades para muitas cidades do Nordeste. O estado da Paraíba foi o que apresentou o maior contingente médio de cidades com maior gasto na função, com destaque para o Município de Vieirópolis, que indicou o resultado mais expressivo em 2008, o maior da série. Salvo problemas no envio de informações para o Tesouro Nacional, a análise individual comprova que os municípios com resultados expressivos geralmente possuem as seguintes particularidades ambientais: extração mineral (que gera um montante de recursos transferidos pelas empresas exploradoras para a conta das prefeituras), áreas de preservação ambiental e/ou atividades turísticas intensivas, que exigem um esforço federalista trino.

Quadro 9. Índice de Gestão Pública ambiental (máximo) para os pequenos Municípios (em \%)

\begin{tabular}{|c|c|c|c|c|c|c|c|c|c|c|c|}
\hline Estado & 2002 & 2003 & 2004 & 2005 & 2006 & 2007 & 2008 & 2009 & 2010 & 2011 & 2012 \\
\hline ALAGOAS & 19,20 & 10,56 & 8,53 & 1,12 & 1,44 & 1,48 & 1,29 & 1,87 & 1,95 & 4,12 & 2,95 \\
\hline BAHIA & 19,94 & 2,80 & 3,01 & 2,41 & 9,82 & 4,11 & 1,73 & 20,75 & 2,11 & 1,51 & 3,84 \\
\hline CEARÁ & 11,93 & 8,48 & 14,98 & 5,42 & 5,41 & 5,41 & 5,29 & 23,64 & 2,23 & 4,44 & 13,74 \\
\hline MARANHÃO & 5,36 & 5,70 & 1,48 & 2,68 & 6,48 & 5,48 & 3,88 & 2,27 & 4,12 & 2,16 & 3,04 \\
\hline PARAIIBA & 11,53 & 5,92 & 8,09 & 4,80 & 9,83 & 4,64 & 26,08 & 3,78 & 9,36 & 15,13 & 19,92 \\
\hline PERNAMBUCO & 10,29 & 4,90 & 6,53 & 2,81 & 8,96 & 5,38 & 6,01 & 2,95 & 4,94 & 6,59 & 5,10 \\
\hline PIAUÍ & 19,78 & 23,54 & 9,72 & 6,66 & 8,20 & 8,37 & 8,64 & 4,39 & 3,84 & 0,00 & 0,00 \\
\hline $\begin{array}{l}\text { RIO GRANDE DO } \\
\text { NORTE }\end{array}$ & 5,81 & 5,49 & 4,44 & 5,60 & 8,74 & 6,12 & 30,01 & 3,94 & 5,90 & 4,69 & 4,55 \\
\hline SERGIPE & 0,00 & 3,65 & 3,55 & 6,31 & 6,20 & 5,23 & 13,73 & 6,85 & 0,00 & 0,00 & 0,00 \\
\hline
\end{tabular}

Fonte: FINBRA. Elaboração do Autor.

As subfunções ambientais (gráfico 1) indicam particularidades estaduais. Os estados do Ceará, Piauí e Pernambuco apresentam fortes despesas com recursos hídricos, justificado, principalmente pelo protagonismo cearense na gestão hídrica, dado que possui o maior semiárido da relação nordeste. Outro fator relevante é o polígono da seca, decreto Lei que estabelece a relação dos municípios entre os estados do Maranhão e Espírito Santo com índice de baixa precipitação pluviométrica, índice de aridez e risco de seca. Dos 1348 municípios que fazem parte do polígono, 1262 encontram-se nos 9 estados do Nordeste (93,62\% da área total da região).

Não obstante, as secretarias de meio ambiente dos três estados possuem planos estratégicos ambientais que colocam as cidades em ênfase no processo de gestão hídrica, através de parcerias junto aos municípios. Os estados da Bahia e Rio Grande do Norte possuem um maior fluxo financeiro na preservação ambiental, comprovadas pelas áreas de proteção existentes nessas duas cidades. Os demais estados apresentam a subfunção "outras despesas ambientais" mais representativas, não sendo possível identificar a natureza dos gastos. 
Gráfico 1 - Participação das subfunções ambientais (em \%)*

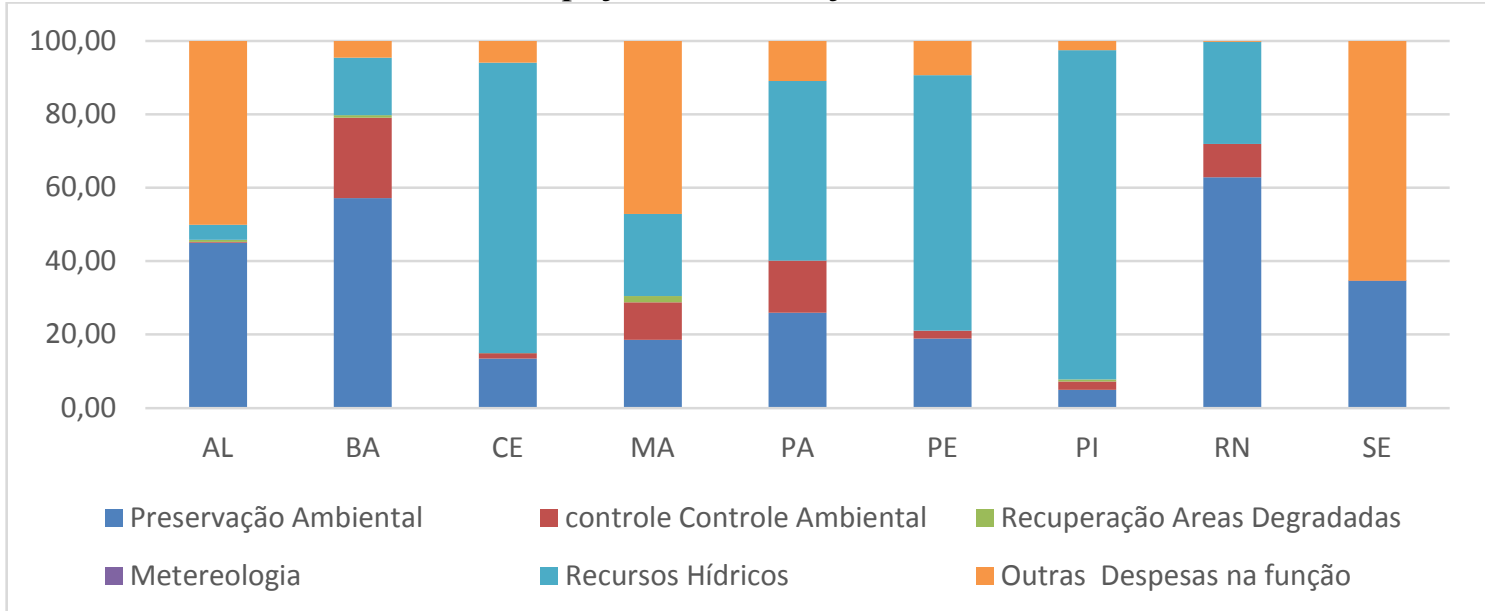

*) Média dos resultados ente os anos de 2005 a 2014.

Fonte: FINBRA. Elaboração do Autor.

O índice "razão entre gestão ambiental e PIB" não apresentou médica acima de 0,00 para os estados nordestinos, considerando a média dos resultados. Já os valores extremos (quadro 10) não foram significativos para nenhum estado, dado que não ultrapassou $1 \%$ do produto das pequenas Cidades. Esses dados explicam o descompromisso com ao desenvolvimento sustentável, pois:

[...] enquanto utilizam os recursos naturais para produzir riquezas, as respectivas cidades não realizam investimento em programas e ações que buscam a conservação e restauração ambiental, diante do quadro apresentado, os municípios não estão seguindo o princípio da sustentabilidade, podendo comprometer o desenvolvimento das futuras gerações. (Almeida, 2010, p.111)

Embora a descrição do autor supracitado evidencie municípios com maiores populações, a mesma realidade é visualizada nas cidades pequenas e, em grande maioria, com situação financeira delicada, dada insuficiência fiscal existente.

Quadro 10. Razão entre Gestão ambiental e PIB (máximo) para os pequenos municípios (em \%)

\begin{tabular}{|c|c|c|c|c|c|c|c|c|c|}
\hline Estado & $\mathbf{2 0 0 2}$ & $\mathbf{2 0 0 3}$ & $\mathbf{2 0 0 4}$ & $\mathbf{2 0 0 5}$ & $\mathbf{2 0 0 6}$ & $\mathbf{2 0 0 7}$ & $\mathbf{2 0 0 8}$ & $\mathbf{2 0 0 9}$ & $\mathbf{2 0 1 0}$ \\
\hline ALAGOAS & 0,0094 & 0,0076 & 0,0020 & 0,0127 & 0,0035 & 0,0038 & 0,0043 & 0,0041 & 0,0060 \\
\hline BAHIA & 0,0475 & 0,0076 & 0,0086 & 0,0040 & 0,0056 & 0,0063 & 0,0102 & 0,0058 & 0,0075 \\
\hline CEARÁ & 0,0475 & 0,0076 & 0,0086 & 0,0040 & 0,0056 & 0,0063 & 0,0102 & 0,0058 & 0,0075 \\
\hline MARANHÃO & 0,0244 & 0,0150 & 0,0055 & 0,0133 & 0,0223 & 0,0211 & 0,0323 & 0,0174 & 0,0303 \\
\hline PARAÍBA & 0,0704 & 0,0395 & 0,0231 & 0,0400 & 0,0548 & 0,0288 & 0,1426 & 0,0279 & 0,0947 \\
\hline PERNAMBUCO & 0,0323 & 0,0174 & 0,0336 & 0,0124 & 0,0385 & 0,0219 & 0,0406 & 0,0159 & 0,0324 \\
\hline PIAUÍ & 0,1917 & 0,1715 & 0,0646 & 0,0893 & 0,1298 & 0,1018 & 0,1708 & 0,1148 & 0,0507 \\
\hline $\begin{array}{c}\text { RIO GRANDE } \\
\text { DO NORTE }\end{array}$ & 0,0156 & 0,0100 & 0,0125 & 0,0246 & 0,0585 & 0,0321 & 0,1323 & 0,0233 & 0,0329 \\
\hline SERGIPE & 0,0438 & 0,0000 & 0,0477 & 0,0727 & 0,1303 & 0,1111 & 0,1012 & 0,1394 & 0,0769 \\
\hline
\end{tabular}

Fonte: FINBRA. IPEADATA. Elaboração do Autor.

O índice de gestão ambiental por área (quadro 11) relaciona o total gasto com recursos ambientais e a área $\left(\mathrm{em} \mathrm{km}^{2}\right)$. Embora não segmente entre áreas rural e urbana, esse indicador 
oferece a oportunidade de avaliar o esforço municipal na proteção do meio ambiente. Os resultados médios para o período em análise foramnulos para todos os estados, mas os números máximos indicam variações, com destaque para a Paraíba, que concentrou os melhores resultados. Considerando que os pequenos municípios tendem a possuir extensão territorial variável, o indicador merece uma análise mais aprofundada das particularidades de cada município.

Quadro 11. Índice de gestão ambiental por área (máximo) para os pequenos municípios (em R $\$$ )

\begin{tabular}{|c|r|r|r|r|r|r|r|r|r|r|}
\hline Estado & $\mathbf{2 0 0 2}$ & $\mathbf{2 0 0 3}$ & $\mathbf{2 0 0 4}$ & $\mathbf{2 0 0 5}$ & $\mathbf{2 0 0 6}$ & $\mathbf{2 0 0 7}$ & $\mathbf{2 0 0 8}$ & $\mathbf{2 0 0 9}$ & $\mathbf{2 0 1 0}$ \\
\hline ALAGOAS & 522 & 1552 & 448 & 3376 & 1472 & 1832 & 1959 & 2024 & 3711 \\
\hline BAHIA & 4262 & 754 & 1058 & 2030 & 4416 & 1370 & 6068 & 37381 & 691 \\
\hline CEARÁ & 1884 & 617 & 771 & 365 & 370 & 444 & 1421 & 1071 & 1370 \\
\hline MARANHÃO & 977 & 364 & 203 & 290 & 1738 & 1330 & 939 & 896 & 1892 \\
\hline PARAÍBA & 4689 & 2921 & 7942 & 3833 & 11666 & 21950 & 4912 & 3378 & 17331 \\
\hline PERNAMBUCO & 1061 & 4322 & 4876 & 2025 & 8549 & 2434 & 3074 & 8701 & 5805 \\
\hline PIAUÍ & 603 & 614 & 8813 & 3979 & 3704 & 5537 & 6868 & 927 & 419 \\
\hline RIO GRANDE DO NORTE & 3086 & 1285 & 1318 & 1671 & 3197 & 5418 & 11158 & 7990 & 13961 \\
\hline SERGIPE & 404 & 522 & 650 & 1.262 & 1.228 & 1.112 & 5.577 & 3.118 & 970 \\
\hline
\end{tabular}

Fonte: FINBRA. IPEADATA. Elaboração do Autor.

$\mathrm{Na}$ avaliação do índice de gestão per capita (quadro 12) apenas o estado de Sergipe apresentou resultados médios positivos, nos anos de 2006 e 2007, influenciados pela menor população, dentre os estados pesquisados. Todavia, os resultados foram ínfimos, confirmando a nulidade do indicador.

Quadro 12. Índice de Gestão per capita para os pequenos Municípios (em R \$)

\begin{tabular}{|c|c|c|c|c|c|c|c|c|c|c|c|c|c|c|}
\hline Estado & $\mathbf{2 0 0 2}$ & $\mathbf{2 0 0 3}$ & $\mathbf{2 0 0 4}$ & $\mathbf{2 0 0 5}$ & $\mathbf{2 0 0 6}$ & $\mathbf{2 0 0 7}$ & $\mathbf{2 0 0 8}$ & $\mathbf{2 0 0 9}$ & $\mathbf{2 0 1 0}$ & $\mathbf{2 0 1 1}$ & $\mathbf{2 0 1 2}$ & $\mathbf{2 0 1 3}$ & $\mathbf{2 0 1 4}$ \\
\hline ALAGOAS & 0,00 & 0,00 & 0,00 & 0,00 & 0,00 & 0,00 & 0,00 & 0,00 & 0,00 & 0,00 & 0,00 & 0,00 & 0,00 \\
\hline BAHIA & 0,00 & 0,00 & 0,00 & 0,00 & 0,00 & 0,00 & 0,00 & 0,00 & 0,00 & 0,00 & 0,00 & 0,00 & 0,00 \\
\hline CEARÁ & 0,00 & 0,00 & 0,00 & 0,00 & 0,00 & 0,00 & 0,00 & 0,00 & 0,00 & 0,00 & 0,00 & 0,00 & 0,00 \\
\hline MARANHÃO & 0,00 & 0,00 & 0,00 & 0,00 & 0,00 & 0,00 & 0,00 & 0,00 & 0,00 & 0,00 & 0,00 & 0,00 & 0,00 \\
\hline PARAÍBA & 0,00 & 0,00 & 0,00 & 0,00 & 0,00 & 0,00 & 0,00 & 0,00 & 0,00 & 0,00 & 0,00 & 0,00 & 0,00 \\
\hline PERNAMBUCO & 0,00 & 0,00 & 0,00 & 0,00 & 0,00 & 0,00 & 0,00 & 0,00 & 0,00 & 0,00 & 0,00 & 0,00 & 0,00 \\
\hline PIAUÍ & 0,00 & 0,00 & 0,00 & 0,00 & 0,00 & 0,00 & 0,00 & 0,00 & 0,00 & 0,00 & 0,00 & 0,00 & 0,00 \\
\hline $\begin{array}{c}\text { RIO GRANDE DO } \\
\text { NORTE }\end{array}$ & 0,00 & 0,00 & 0,00 & 0,00 & 0,00 & 0,00 & 0,00 & 0,00 & 0,00 & 0,00 & 0,00 & 0,00 & 0,00 \\
\hline SERGIPE & 0,00 & 0,00 & 0,00 & 0,00 & 1,78 & 0,75 & 0,00 & 0,00 & 0,00 & 0,00 & 0,00 & 0,00 & 0,00 \\
\hline
\end{tabular}

Fonte: FINBRA. Elaboração do Autor.

A relação dos resultados máximos obtidos (quadro 13), mais uma vez indica uma variação, a depender dos municípios que compõe cada estado. Em média, o estado do Rio Grande do Norte apresentou a melhor relação gasto ambiental/população, seguido por Sergipe e Paraíba. Embora possua a segunda menor população, Alagoas foi o que apresentou menor relação média. 
Quadro 13. Índice de Gestão per capita (máximo) para os pequenos Municípios (em R \$)

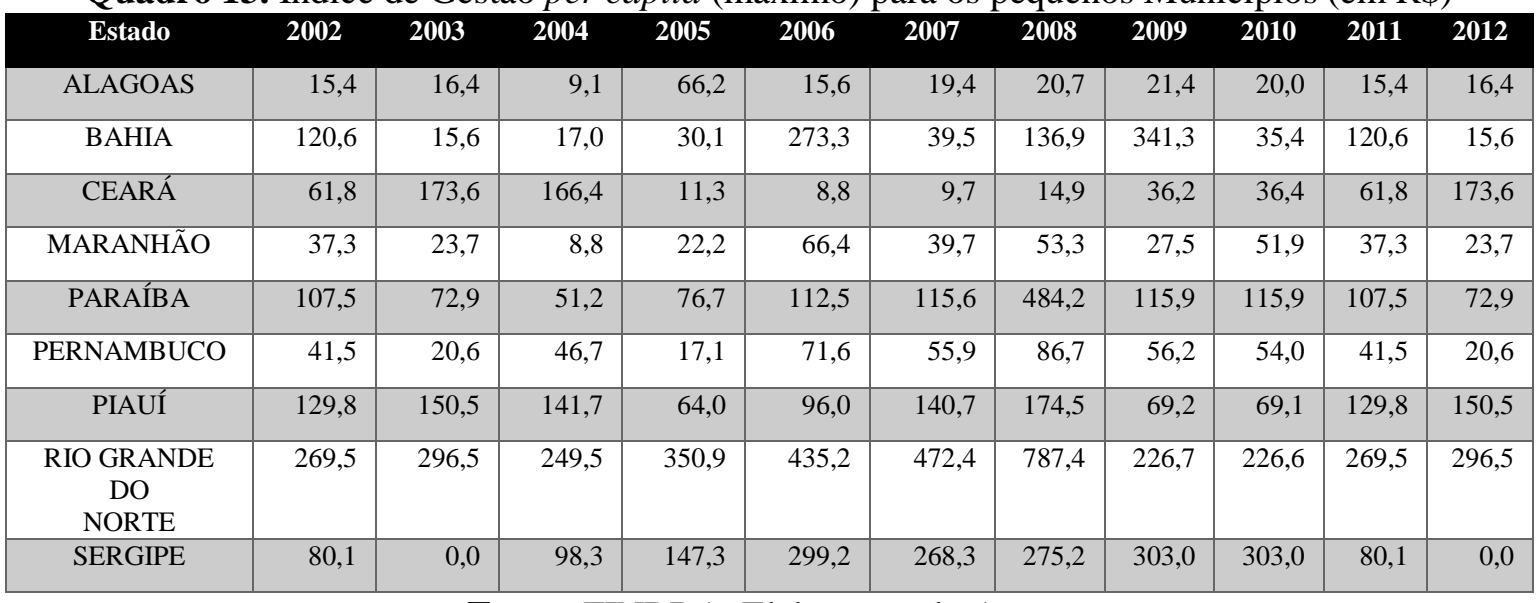

Fonte: FINBRA. Elaboração do Autor.

Diante do contexto financeiro ambiental delicado, uma alternativa para ampliar os orçamento das prefeituras, diante da incapacidade de ampliar as receitas via recursos próprios, seriam os convênios entre as prefeituras municipais e os demais entes federados. Porém, os dados indicam a quase inexistência de convênios entre união/estados/municípios. Entre 2005/14, não foi registrado nenhum dado contábil referente a convênios entre o Governo dos estados e prefeituras municipais, tornando o índice de transferências estaduais igual a zero para todos os anos da análise.

No tocante aos Convênios com o Governo Federal, os resultados médios também foram nulos, embora se observe alguns fluxos financeiros para cidades específicas, porém sem periodicidade.

\section{CONSIDERAÇÕES FINAIS}

Observando o esforço individual de cada prefeitura, percebe-se a baixa relevância do total de recursos investidos em gestão ambiental, que não supera 1\% do Produto Interno Bruto - PIB, para todos os municípios investigados, independentemente da densidade populacional ou da renda disponível em cada um deles. No tocante aos convênios estaduais entre os entes subnacionais (estados e municípios), não foi identificada a celebração de acordos. Já quanto aos convênios federais (União e municípios), embora diversos tenham sido celebrados, o impacto desses aportes de recursos mostra-se pouco expressivo, na medida em que, na última década (entre os anos de 1996 e 2016), o total de municípios que firmaram mais de um convênio não ultrapassou o percentual de $12 \%$ das cidades nordestinas. A análise da natureza de cada um desses acordos demonstra que, sob o ponto de vista da gestão ambiental, a sua finalidade se distancia das ações de defesa e preservação do meio ambiente, dado que a maior parte dos recursos são destinados a obras pontuais, como a construção de lagoas/barragens/poços, ou ações pós-enchentes; gestão de recursos hídricos; e implantação de aterros sanitários. 
A desagregação do tecido federativo manifesta-se no baixo nível de integração entre os diferentes níveis de governo, sendo a gestão ambiental do território relegada ao nível municipal, porém sem uma autonomia institucional e um aporte de recursos compatível com tais atribuições. Vale ponderar, diante disso, que a própria natureza e complexidade da gestão ambiental demanda uma articulação territorializada do poder público, mediante uma concepção do pacto federativo enquanto um fenômeno também concretamente territorial, marcado por uma heterogeneidade de conflitos e mecanismos de conciliação. A esse respeito, importa mencionar que as próprias "Áreas de Proteção Ambiental" - cujo controle e preservação são de responsabilidade municipal -, frequentemente, extrapolam os limites territoriais das cidades, abarcando dois ou mais municípios, o que demanda uma atuação pública articulada a partir também de outros níveis federativos, ganhando relevância, assim, a dimensão territorialfederativa da gestão ambiental, enquanto instância una, na qual se materializa a co-presençade interesses e objetivos dos diversos níveis de governo.

\section{REFERÊNCIAS BIBLIOGRÁFICAS}

AFFONSO, R. B. A. O Federalismo e as teorias hegemônicas da Economia do Setor Público na segunda metade do século XX: um balanço crítico. 2003. 268 f. Tese (Doutorado em Economia)Instituto de Economia da Unicamp, Campinas, 2003.

Descentralização e reforma do Estado: a federação brasileira na encruzilhada. Revista Economia e Sociedade, Campinas, v. 14, p. 127-152, jun. 2000.

ALMEIDA, Thiago Alexandre das Neves.2010. Evidenciação dos Gastos com Gestão Ambiental em Municípios Nordestinos no Período de 2005 à 2008. Dissertação (Mestrado em Ciências Contábeis). Pós-Graduação Multiinstitucional em Ciências Contábeis da Universidade de Brasília; Universidade Federal da Paraíba e Universidade Federal do Rio Grande do Norte: João Pessoa.

BRASIL. Constituição da República Federativa do Brasil de 1988. Brasília, DF. Disponível em: http://www.planalto.gov.br/ccivil_03/constituicao/constitui\%C3\%A7ao.htm

Lei Complementar 101, de 4 maio 2000. Brasília, DF. Disponível em: http://www.planalto.gov.br/ccivil_03/leis/LCP/Lcp101.htm

.Lei Complementar $\mathbf{N}^{\mathbf{0}}$ 140, de 8 de dezembro de 2011. Brasília, DF. Disponível em: http://www.planalto.gov.br/ccivil_03/Leis/LCP/Lcp140.htm.

LEI $\mathbf{N}^{\circ}$ 6.938, de 31 de agosto de 1981. Brasília, DF. Disponível em: http://www.planalto.gov.br/ccivil_03/leis/16938.htm.

Instituto Brasileiro de Geografia e Estatística. Perfil dos Municípios 2013. Rio de Janeiro, 2014.

BUCHANAN, J. M. Federalism as an Ideal Political Order and an Objective for Constitutional Reform. Publius: The JournalofFederalism, v. 25, n. 2, p. 1-9, 1995.

CARLO, Sandra de. 2006. Gestão ambiental nos municípios brasileiros: impasses e heterogeneidade.Tese (Doutorado em desenvolvimento sustentável). Universidade de Brasília. Brasília/DF.

CNM.2008. Confederação Nacional dos Municípios. Meio Ambiente: Desafio e Oportunidade para os Gestores Municipais / Confederação Nacional dos Municípios - Brasília/DF: CNM.

DYE, T. R. American federalism: competition among governments. Massachusetts/Toronto: Lexington Books, 1990. p. 219. 
FIORI, J. L. O federalismo diante do desafio da globalização. In: AFFONSO, R. B. A.; SILVA, P. L. (Orgs.). A federação em perspectiva. São Paulo: Fundap, 1995.

HARMES, A. The PoliticalEconomyofOpenFederalism. CanadianJournalofPoliticalScience, v. 40, n. 2, p. 417-437, 2007.

LEME, Taciana Matos. 2016. Governança ambiental no nível municipal., in Governança ambiental no Brasil : instituições, atores e políticas públicas / organizadora: Adriana Maria Magalhães de Moura . Brasília : IPEA.

LEME, Taciana Matos.2010. Os municípios e a política nacional do meio ambiente. Revista planejamento e políticas públicas. Brasília : IPEA.

LYNCH, G. P. Protecting Individual RightsThrough a Federal System: James Buchanan'sViewofFederalism. Publius: The JournalofFederalism, v. 34, n. 4, p. 153-168, 2004.

MALHEIROS. Tadeu Fabricio. Phlippi Jr., Arlindo. Coutinho, Sonia Maria Viggiani. 2008. Agenda 21 Nacional e Indicadores de Desenvolvimento Sustentável: contexto brasileiro. Revista Saúde e Sociedade: São Paulo.

NEVES, Estela Maria Souza Costa .2014.Política e gestão ambiental no contexto municipal. Cadernos ADENAUER Xx: São Paulo.

NEVES, Estela Maria Souza Costa .2006. A política ambiental e os municípios brasileiros. Tese (Doutorado em Ciências Sociais em Desenvolvimento, Agricultura e Sociedade). Universidade Federal Rural do Rio de Janeiro: Rio de Janeiro.

OLIVEIRA, F. A. Teorias da federação e do federalismo fiscal: o caso do Brasil. Belo Horizonte: EG/FJP, 2007 (Texto para Discussão).

PHILlIP JR, Arlindo. ROMÉRO. Marcelo de Andrade. BRUNA. Gilda Collet.(editores). Curso de gestão ambiental.Barueri,SP: Manole, 2004.

REZENDE, F.; OLIVEIRA, F.; ARAÚJO, É. O dilema fiscal: remendar ou reformar. Rio de Janeiro: Editora FGV, 2007. p. 208.

SCARDUA, Fernando Paiva. 2003. Governabilidade e descentralização da gestão ambiental no Brasil.Tese. Universidade Federal de Brasília: Distrito Federal.

THE WORLD BANK. World development report $1999 / 2000$ - entering the $21^{\text {st }}$ century. New York: Oxford University Press, 2000. 